\title{
Reestruturação de layout baseado no mapeamento de fluxo de valor: Um estudo em uma indústria de confecções
}

RESUMO

Cristiano Henrique Antonelli da Veiga

chadaveiga@ufu.br

Universidade Federal de Uberlândia (UFU), Uberlândia, Minas Gerais, Brasil.

Anderson Luis Schmitz anderson.ximites@hotmail.com Universidade Federal de Santa Maria (UFSM), Palmeira das Missões, Rio Grande do Sul, Brasil.
O objetivo geral deste trabalho foi elaborar e analisar o mapa do fluxo de valor no processo de fabricação de roupas em jeans em uma indústria de confecções. A metodologia utilizada foi a pesquisa-ação, aplicando técnicas de observação direta e coleta de dados primários no chão de fábrica, acompanhando as operações de produção. O estudo foi norteado principalmente para o modelo de uma coleção de calça jeans masculina tradicional, devido ser produto o carro chefe da empresa. Foi utilizada a ferramenta mapeamento do fluxo de valor para identificar os fluxos dos processos, dos materiais e de informações correntes na empresa, na qual foram identificadas gargalos, tais como, fluxos truncados, grande estoque de material aguardando processamento, necessidade de um espaço físico maior, tempo de agregação de valor irregular entre os setores assim como necessidade do aumento do número de máquinas ou maior eficiência das mesmas. Com os dados obtidos neste estudo foi possível projetar um novo arranjo físico para todos os departamentos da empresa, melhorando a eficiência dos fluxos, contribuindo para a redução do tempo de ciclo e do lead time da produção.

PALAVRAS-CHAVE: Mapeamento de fluxo de valor. Leiaute. Confecção. 


\section{INTRODUÇÃO}

Com o crescente avanço em pesquisas e criação de ferramentas de controle no ramo industrial, possibilitaram-se às empresas ter maior gerenciamento de sua organização, diminuindo seus custos e maximizando suas produções com os recursos disponíveis. Como resultado, além de manter a mesma ativa no mercado, deve apresentar rentabilidade a seus acionistas.

O mercado têxtil é caracterizado por muitas empresas que atuam no segmento provocando uma concorrência acirrada. Além de concorrer com o mercado interno, o setor sofre muito com a onda de importação oriundas principalmente de mercados asiáticos. Embora o Brasil seja o quarto produtor mundial de confecções e possuir a quinta maior industrial têxtil mundial ele participa com aproximadamente $0,4 \%$ desse mercado (NOGEUIRA; COTRIM; LEAL, 2017).

Para superar esta situação, uma das maneiras possíveis é utilizar-se de ferramentas de gestão e de estratégias de produção adequadas a esta realidade com o intuito de minimizar seus custos de produção, garantindo qualidade e proporcionando o crescimento da empresa.

Acompanhar o cenário e tendências da moda é uma tarefa que exige dos profissionais da área estejam sempre atualizados com os lançamentos de novos modelos. Para que a planta industrial tenha flexibilidade e condições de dar as respostas às necessidades do mercado nos tempos de cada coleção, além de várias ações de desenvolvimento de produtos e sua produção (VEIGA; CERESA, 2013), faz-se necessário manter um arranjo físico adequado a cada nova coleção, podendo gerar resultados significativos ao final de cada ciclo.

Em vistas ao crescimento da organização, foco deste trabalho, verificou-se que a organização atual apresenta problemas de fluxo produtivo e, com a ampliação de seu espaço físico possibilita projetar um novo fluxo que agregue valor no processo de fabricação do seu principal produto. Assim, verificou-se a necessidade da realização deste trabalho, que pelo uso da ferramenta Mapeamento do Fluxo de Valor, busca identificar os fluxos de materiais, processos e de informações correntes e projetar um novo arranjo físico, visando a diminuição de tempos de ciclo e do lead time da produção.

Visto a importância e a necessidade de ferramentas que auxiliem na tomada de decisões em empresas do ramo de confecções foi desenvolvida uma pesquisaação, com foco na fabricação do produto calça jeans masculina tradicional. Buscou-se analisar o atual cenário produtivo da empresa, identificando possíveis anomalias e, propondo soluções a fim de melhorar a eficiência dos seus processos.

O trabalho foi dividido em etapas para uma melhor compreensão do assunto. Primeiramente foi abordada a revisão da literatura referente ao tema da pesquisa, seguido pela metodologia utilizada. Em seguida é apresentado o levantamento e uma análise dos dados obtidos ao decorrer do estudo, as melhorias propostas e por fim são apresentadas as considerações finais do trabalho e as referências. 


\section{REFERENCIAL TEÓRICO}

A atividade desenvolvida pelo setor de confecção tem como principais características a confecção de peças e acessórios do vestuário, dentre elas roupas de segmento de moda, esporte, moda social, profissionais, íntima, exclusiva, dentre outros (DUTRA et al, 2011). Também, este segmento, confecciona peças residenciais como cortinas, tapetes, edredons, almofadas, capas dentre outros, além de confeccionar itens com tecidos para o vestuário focado em artefatos de segurança industrial e pessoal que contém além de tecido, outros materiais inseridos ao produto acabado específicos deste setor. Portanto a Indústria de Confecção tem como atividade fim, fabricar e comercializar peças de vestuário e artigos de origens têxteis (SEBRAE, 2010).

De acordo com Seixas e Catoira (2013), o Brasil vem vivendo uma identidade cultural construída, ao longo do tempo, por marcas nacionais, entrando no mercado da moda com um toque brasileiro focado principalmente nos elementos como natureza, praia, ecologia e artesanato além de ser influenciado pelas tendências internacionais. Devido à forte variedade de influencias étnica e cultural, a produção e o design brasileiro vêm agregando valor aos produtos, tomando espaço nacional motivando a competitividade de pequenas a grandes empresas, que investem em estilo e em tecnologia, proporcionando inovação, qualidade e alta produção de vestuários.

Ainda Seixas e Catoira (2013) afirmam que o Made in Brazil tem potencial de articulação e está no mercado da moda nacional e internacional, levando um design brasileiro com potencial, devido à diversidade dos fatores que permeiam o povo brasileiro como: música, esporte, dança e estilo. Um setor relevante e bem desenvolvido no vestuário nacional é o jeans, contando com empresas de indústria têxtil e de confecção que lutam para ser competitivas e de qualidade, geradoras de valor ao produto, trazendo estilo e conforto ao consumidor. As empresas brasileiras agregam valores a seus produtos expressando a alegria, espontaneidade, criatividade, simplicidade, o luxo tropical e a sensualidade, harmonizando diversos elementos, oferecendo um conceito com a cara do Brasil.

Conforme Sant'Anna (2010), a cadeia produtiva da moda é composta por diferentes etapas produtivas, que são inter-relacionadas umas com as outras, seja no seu beneficiamento ou na sua comercialização, cada etapa exige o correto beneficiamento, contribuindo para o desenvolvimento da fase seguinte, na qual é encaminhada dando continuidade à cadeia sucessivamente até chegar às mãos do cliente. De forma linear, da matéria prima até o produto final comercializado, são considerados os seguintes estágios no processo produtivo: (a) produção da matéria prima; (b) fiação; (c) tecelagem; (d) beneficiamento / acabamento; (e) confecção; (f) mercado. Em meio estes estágio existe uma série de operações mecânicas e manuais têxteis e de confecção, além de serviços e funções corporativas que interagem com a cadeia.

Um setor que oportuniza maior valor agregado no produto e está dentro da cadeia produtiva da moda é a da indústria de transformação, a qual conta com as atividades de: (a) preparação; (b) beneficiamento; (c) acabamento; (d) confeccionados têxteis. São desenvolvidas por uma estrutura industrial diferenciada com uma grande divisibilidade do processo produtivo. Este setor de transformação é complexo, fragmentado e intensivo em mão-de-obra (SANT'ANNA, 2010). 
Ainda Sant'Anna (2010) afirma que o setor tem a capacidade de confeccionar roupas e acessórios de vestuário em geral: cama, mesa, banho e artigos para casa, peças de uso específico como meias e acessórios entre outros itens. Devido à possibilidade de separação das tarefas da indústria de transformação, sendo a criação, preparação, modelagem, corte e costura entre outras atividades, possibilita trabalhar minuciosamente desmembrando cada processo, a fim de regular a qualidade do produto final e buscar maior eficiência na sua produção.

Deste desmembramento na produção, é possível analisar cada processo e estudar os fluxos de materiais e de informações a fim de identificar gargalos trabalhando na eliminação dos mesmos, visando à qualidade e produtividade do processo. Este trabalho se deve a administração da produção, que através de conhecimentos na área contribuem para o desenvolvimento da produção.

\section{PLANEJAMENTO DE LEIAUTE (ARRANJO FÍSICO)}

Para que determinada operação obtenha maiores resultados é necessário o planejamento adequado, uma instalação organizacional, seja ela de serviços ou de bens físicos, deve ter seus centros de trabalho bem orientados a fim de se definir o melhor leiaute possível (Davis, Aquilano e Chase, 2001).

Todo o planejamento de leiaute tem o intuito de tornar mais simplificada e suave a movimentação do trabalho por meio de um sistema, seja essa movimentação referente ao fluxo de pessoas ou de materiais na produção de bens ou na prestação de serviços ao cliente, tornando o sistema mais ágil e eficaz com os recursos disponíveis (GADELHA et al., 2015). O leiaute é a maneira que os recursos físicos, que ocupam espaço dentro de uma organização, podendo ser desde móveis, pessoas, operações, máquinas, departamentos entre outros, estão posicionados para o desenvolvimento da atividade (GAITHER; FRAZIER, 2007).

Segundo Moreira (2008), as decisões e planejamentos sobre um novo leiaute, não ocorrem apenas quando a empresa projeta novas instalações ou aumento de suas instalações atuais, mas também em sua estrutura já existente, sempre que observadas oportunidades de melhorias nos processos, aumento da demanda de produtos, ineficiência de operações, altos índices de acidentes, alterações no produto ou serviço, alterações na quantidade de produtos ou no giro de clientes, entre outros motivos identificados, possibilitando ajustes e adequações visando melhores rendimentos dos processos.

A formação de um leiaute adequado para o tipo de serviço ou bem a ser desenvolvido, é fundamental para que a organização possa usufruir a melhor maneira seu espaço físico e os recursos disponíveis, tornado se eficaz no que faz, consequentemente colaborando para ganhos produtivos e financeiros.

Corrêa e Corrêa (2006) atendem que não há um tipo de leiaute ideal que atenderá todas as necessidades de uma organização considerando todos os critérios de desempenho ao mesmo tempo, mas que atendem os níveis aceitáveis de eficiência e eficácia dos processos e operações. Portanto o projeto de leiaute poderá enfatizar atividades que adicionem valor, ou a eliminação de atividades que não agreguem valor, atividades que contribuem para a obtenção de valor como diminuição dos custos de movimentação de materiais, utilizar de forma eficiente os espaços físicos disponíveis, redução de tempo de ciclo de operações, 
facilitar a movimentação dos fluxos de materiais e de pessoas entre outras atividades.

Em vista aos benefícios proporcionados pela sua aplicação, abordaremos os principais tipos de leiaute que trata a literatura e, em seguida, a ferramenta mapeamento do fluxo de valor como meio para contribuir na elaboração e análise do leiaute da empresa estudada.

\section{MAPEAMENTO DO FLUXO DE VALOR}

Nesse trabalho optou-se pela utilização da ferramenta de mapeamento do fluxo de valor conforme os preceitos de Rother e Shook (2003) para analisar o atual arranjo físico da empresa estudada. O mapeamento do fluxo de valor tornase uma ferramenta que auxilia a análise dos processos e fluxos de uma organização. Com ele é possível fazer o levantamento e mapeamento dos processos com o intuito de verificar e identificar minuciosamente supostos gargalos, a fim de eliminá-los e dar ênfase as tarefas que agregam valor ao produto.

Um fluxo de valor é toda a ação que agregue valor ou não em uma operação de um produto, seja esta operação referente ao fluxo de produção sendo desde a matéria-prima até chegar ao consumidor final, ou a operação de produção de parte de um produto até seu término por uma empresa sistemista de um fabricante (BUENO; VEIGA, 2016).

O mapeamento do fluxo de valor é uma ferramenta, um mapa que auxilia a enxergar e entender o fluxo de material e de informações na medida em que o produto segue o seu fluxo de produção, passando de uma unidade a outra, facilitando a enxergar os pontos onde há desperdícios ou quando o fluxo atual de informações ou de processos podem delimitar ou reduzir a capacidade dinâmica de funcionamento de uma organização (VEIGA; CEREZA, 2013). O fluxo completo pode ser desde a elaboração da matéria-prima até a entrega do produto ao consumidor final, este seria o mapeamento completo do fluxo de valor de um bem.

O mapa pode ser elaborado com foco em uma organização geradora de valor ou até mesmo em uma única célula ou unidade de produção da empresa. Esse mapeamento se faz necessário para identificar as etapas da produção que realmente agreguem valor ao produto e também enxergar as fontes de desperdício existentes no atual processo. Ainda, contribui para elaboração de novas estratégias, alocando equipamentos ou mão de obra, sendo também referência para a implementação da manufatura enxuta (ROTHER; SHOOK, 2003).

O mapeamento é uma ferramenta qualitativa, que é desenhado detalhadamente seus fluxos de materiais e de informações, a fim de descrever como a unidade de produção está operando, conhecendo a fundo o chão de fábrica, podendo a partir daí, analisar e desenhar o estado futuro, com foco em um fluxo de materiais e de informações mais próximos de um estado ideal, criando valor a cada processo de operação (ELIAS; OLIVEIRA; TUBINO, 2011).

Dentro de uma fábrica há dois tipos de fluxos, sendo o de matérias e o de informações, onde ambos devem ser mapeados, o fluxo de informações nos diz para cada processo o que deve ser fabricado ou ser feito em seguida, e o fluxo de 
materiais é a própria circulação dos produtos e materiais necessários para a elaboração do produto. O mapeamento ajudará a enxergar e focar no fluxo, com o intuito de se chegar a um estado ideal ou melhorado (SALGADO et al., 2009).

Esta ferramenta de gerenciamento de processos e planejamento de negócios, também é uma linguagem de comunicação e de entendimento aos colaboradores. Para elaborar o mapa é necessário passar pelas etapas de escolha da família de produtos a ser fabricada, desenhar o mapa do estado atual, com base nele desenhar o estado futuro, e em seguida, implementar o arranjo projetado no mapa de estado futuro.

Um grupo de itens de produtos são considerados uma família quando elas passam por etapas semelhantes de processamento e usam equipamentos comuns nos seus processos. A família de produtos a ser trabalhada será a de maior representatividade no volume da demanda e/ou faturamento da empresa, com objetivo de fazer o mapeamento do fluxo de valor a fim de propor um novo mapa de estado futuro, baseado na família de produtos que mais impacta sobre os resultados e exigências da empresa em relação ao mercado (SANTOS; GOHR; SANTOS, 2011).

O primeiro passo do mapeamento é desenhar o estado atual de uma família de produtos, o qual será examinado pela análise da atual situação da produção, por meio de coleta de dados a partir do pedido do cliente, passando pelo chão de fábrica e sincronizando informações do fornecedor, usando um conjunto de símbolos para representar os processos e os fluxos de materiais e de informações ocorrentes.

De acordo com Rother e Shook (2003), para a coleta, deve ser utilizado lápis, borracha, papel, calculadora e um cronometro. O fluxo dos materiais deverá ser desenhado da esquerda para a direita na parte inferior do mapa, sendo na mesma sequência das etapas do processo, e não conforme o arranjo físico da fábrica. Já o fluxo de informações é desenhado da direita para a esquerda na parte superior do mapa. A partir deste ponto serão levantado dados e ideias que servirão para desenhar um novo mapa de estado futuro, buscando eliminar desperdícios e agregar valor ao produto.

Alguns dados sugeridos por Rother e Shook (2003) podem ser TAV/Tempo de Agregação de Valor (é o tempo dos elementos de trabalho que efetivamente transformam o produto); TC/Tempo de Ciclo (é o tempo que leva entre um item e o próximo saírem do mesmo processo, dado em segundos); TR/Tempo de Troca (é o tempo que leva para mudar a produção de um tipo de item para outro); Numero de Operadores ( refere-se a quantos operadores são necessários no processo); Tempo de Trabalho Disponível (é o tempo do processo por turno do processo, dado em segundos diminuídos os minutos de descanso, reunião, limpeza); Tempo de Operação ( refere-se ao tempo de utilização efetiva da máquina); TPT/Tamanho do Lote de Produção ( trata-se do tempo total que uma peça leva para percorrer todas as etapas do processo).

Estes tipos de dados são uteis para saber como está sendo o andamento dos processos, São registrados na caixa de dados no momento de desenhar o estado atual, podendo ser utilizados outros tipos de informações identificados pelo pesquisador. 
A fim de eliminar as fontes de desperdício no fluxo de valor, enxergando os problemas básicos que afetam desde a elaboração do projeto, passando pela produção até a entrega do produto ao cliente, são identificados quando desenhado o estado atual, com objetivo de desenhar um novo mapa, com processo que realmente agregue valor e que se processe somente a quantidade certa na hora certa, ligando todos os processos será necessário prospectar um mapa futuro a fim de melhorar o processo atual (LIMA; BISIO; ALVES, 2010). Para a nova projeção, devem ser usadas ferramentas que deem suporte as análises e tomadas de decisões, servindo de suporte para o pesquisador.

Para dar suporte a análise do mapa atual e projetar um mapa futuro com maior confiabilidade, Rother e Shook (2003) sugerem sete procedimentos a serem utilizados:

a) Takt time é um número referência que indica o ritmo de produção em que cada processo deveria produzir, baseado nas vendas a fim de atender a demanda dos clientes, buscando sincronizar os ritmos de produção com os de vendas no processo puxado, ajudando a enxergar como estão sendo processadas as coisas e o que é preciso ser feito, ele é obtido através da divisão de tempo disponível de trabalho (em segundos) pela demanda do cliente (unidades), em turno se houver (SHINGO, 1996);

b) O fluxo contínuo é a maneira mais eficiente de produzir, é utilizado sempre que possível, reduzindo as paradas e desperdícios ocorrentes entre um processo e outro, produzindo uma peça por vez e passando para o processo seguinte;

c) O controle de produção pode ser de duas maneiras. No sistema puxado com supermercado de suprimento é inserido entre dois processos com o intuito de dar a ordem exata de produção ao processo anterior, controlando a produção entre os dois fluxos, assim quem determina a quantidade e quando produzir será o processo seguinte, com o uso de um kanban, esse sistema normalmente é inserido quando o processo anterior é baseado em lotes e o posterior no modelo contínuo, por exemplo. O modelo FIFO (primeiro a entrar, primeiro a sair) também inserido entre dois processos, mas que tem uma quantidade limitada de estoque entre o processo anterior e o processo cliente, assim o processo anterior produz mantendo o limite estipulado (MARTINS; ALT, 2006);

d) Selecionando o processo puxador, é o ponto no fluxo de valor da empresa onde ele controlará o ritmo para os demais processos anteriores, este processo é controlado pelo pedido de produção dos clientes externos, geralmente sendo o último dos processos produtivos da empresa;

e) O nivelamento do mix de produção é a distribuição de diferentes produtos uniformemente durante um período de tempo em menores lotes, quanto mais nivelado o mix, menor será o lead time referente as solicitações de pedidos dos clientes, contribuindo para a diminuição de desperdícios (TUBINO, 2007);

f) Buscando nivelar a produção, será possível projetar com maior precisão tempos de produção, estimativa de entrega ao cliente, ou seja, terá uma produção previsível, que contribuirá para tomar ações corretivas rapidamente. 0 nivelamento poderá ocorrer através de uma prática chamada "retirada compassada", através da liberação no seu sistema puxador onde está ocorre em 
tempos e quantidades de produtos regulares, que deve ocorrer simultaneamente com a retirada de produtos acabados no final do processo;

g) Deve ser desenvolvidas habilidades de produção para desenvolver toda peça todo o dia, ao menos para peças com alto volume, descrevendo a frequência que um processo se modifica para produzir todas as variações de uma peça.

Ainda faz-se necessário o desenvolvimento do mapa de estado futuro, que tem como objetivo desenhar uma cadeia de produção onde os processos são articulados por meio de um fluxo contínuo ou puxados a seu cliente, buscando produzir apenas a quantidade exata na hora exata.

Deverá ser considerado para o desenho do mapa do estado futuro, o projeto do produto, as tecnologias de processo, e a localização e estrutura da planta como dados, a partir daí, buscar identificar e eliminar todas as fontes de desperdício não causadas por estas características, o mais breve possível. Após as primeiras intervenções, poderá ser analisado subsequentemente os itens produto, projeto, tecnologia e localização (SILVA; ALVES, 2011).

O passo final é usar um plano de implementação, descrito em um documento como deve se chegar ao estado futuro, incluindo o mapa do estado futuro. Poderá ocorrer ajustes e melhorias do mapa do estado futuro conforme a progressão da implementação das ações, além de constar um plano anual do fluxo de valor. Ainda pode ser realizadas simulações prévias para se analisar os possíveis ganhos das melhorias sugeridas, bem como realizar os ajustes necessários para a proposta futura (OLIVEIRA; CORRÊA; NUNES, 2014).

O mapeamento do fluxo de valor torna-se inútil se não forem implementadas ações em um curto período de tempo a fim de atingir o estado futuro desenhado. Rother e Shook (2003) sugerem que implantação das tarefas do mapa do estado futuro deve estar dividida a fim de facilitar o entendimento e considerar um processo de construção de uma série de fluxos conectados para uma família de produtos, para que isto ocorra, será dividido o mapa do fluxo de valor em dois "loops": i) Loop puxador: neste loop inclui o fluxo de material e de informação entre o cliente e seu processo puxador, está próximo do final e a maneira de como ele é administrado impactará todos os processos anteriores naquele fluxo de valor; ii) Loops adicionais: situados antes do loop puxador, existem os loops do fluxo de material e do fluxo de informação entre as puxadas.

A divisão em loops é uma boa maneira de dividir esforços de implementação do estado futuro em partes administráveis, deverá ser especificado os objetivos e a meta para cada loop, para ser trabalhado individualmente cada etapa.

Baseado no mapa futuro deve ser criado um plano anual do fluxo de valor onde deve constar o que se planeja fazer e quando, etapa por etapa; metas quantificáveis; pontos de checagem com prazos reais e avaliador definido. Para iniciar, pode se basear nos loops, e buscar a melhoria dentro de cada um, tais como: a) desenvolver um fluxo contínuo que opere baseado no takt time; b) estabeleça um sistema puxado para controlar a produção; c) introduzir o nivelamento; e, d) praticar kaizen continuamente (ROTHER; SHOOK, 2003).

Com o acompanhamento do plano anual do fluxo de valor poderá ser avaliado o desempenho da manufatura, por um determinado período rotineiramente, com um formulário de revisão do fluxo de valor, a fim de avaliar 
e identificar causas que estão retardando o fluxo, trabalhando nelas providenciando o suporte necessário. A vantagem de incorporar esta revisão é de ser uma boa ferramenta para a avaliação de desempenho das implementações, e buscar agir onde as ações não estão sendo cumpridas ou parcialmente cumpridas, os dados para a avaliação devem ser avaliados corretamente para uma real compreensão das ações implantadas anteriormente.

\section{METODOLOGIA}

Inicialmente partiu-se para uma revisão da literatura direcionada ao tema da confecção, do leiaute e de um modelo de aplicação da ferramenta mapeamento do fluxo de valor, a fim de ter uma base consistente de informações e um direcionamento correto para a elaboração do trabalho.

De acordo com Strauss e Corbin (2008), a pesquisa qualitativa refere-se a resultados obtidos em pesquisa, em que não utilizou-se de meios quantificáveis ou estatísticos. Collis e Hussey (2005) afirmam que o método qualitativo é subjetivo e trata-se de estudar e refletir sobre as percepções, a fim de entender as atividades sociais e humanas. Ainda Strauss e Corbin (2008), nos trazem que o método qualitativo é uma maneira de extrair alguma informação intrínseca de um indivíduo, sendo difícil de extrair ou de descobrir pelo uso de outros métodos convencionais. Assim os dados qualitativos foram obtidos por meio de entrevistas com os gestores e colaboradores pertinentes aos processos envolvidos, assim como na descrição dos fluxos e operações do produto estudado.

De acordo com Cooper e Schindler (2011), a pesquisa quantitativa tenta mensurar, descrever, medir, explicar ou prever algo, envolvendo o pesquisador com o objeto estudado, este envolvimento pode ser tanto na coleta como na interpretação dos dados. Para Collis e Hussey (2005), o método quantitativo está focado a mensuração de fenômenos, envolvendo a coleta de dados numéricos, a fim de analisa-los. A abordagem quantitativa será utilizada no levantamento e análise dos dados do fluxo de valor do produto, bem como na cronometragem e cálculos dos tempos nos processos e nos estoques identificados.

O procedimento utilizado na pesquisa é do tipo de pesquisa-ação realizado pela da ação direta do pesquisador tanto nas áreas da prática quanto da pesquisa, de modo a ter características tanto da prática rotineira quanto da pesquisa científica (TRIPP, 2005). Sendo assim a pesquisa-ação é uma forma de investigação-ação, utilizando técnicas de pesquisa com o intuito de informar a ação que é decidida a tomar a fim de aprimorar e contribuir a prática do pesquisador (THIOLLET, 2003).

Para identificar os fluxos de materiais e de informações, processos, estoques entre outras atividades e movimentações pertinentes a elaboração do produto estudado, foram utilizados ícones representativos do fluxo de valor com informações e auxilio de materiais, a fim de explanar tudo o que for pertinente ao processo estudado.

Em seguida foi desenhado e analisado todo o processo produtivo do produto buscando identificar possíveis desperdícios, como tempos de movimentações e de estocagem, em vista a eliminá-los, direcionando o fluxo de uma maneira constante de agregação de valor. 
A coleta dos dados no chão de fábrica foi realizada por meio de observação direta e expressa por símbolos que foram desenhados, como por exemplo, uma caixa de dados contendo registros relativos a cada processo de manufatura, departamento, entre outras informações relevantes, e setas representando fluxo de informação ou material.

Depois de análise do mapa do estado atual, dos gráficos gerados e dos fluxos de materiais em cada departamento, foi elaborado um novo arranjo físico. Em reunião com os donos da fábrica, foram apresentados os dados coletados do fluxo do produto estudado e uma primeira proposta de um novo arranjo físico. Foi discutido, e analisado, apontado necessidades e cuidados com a questão da estrutura física e hidráulica da fábrica, após algumas alterações e melhorias, foi finalizado o leiaute para o fluxo de valor do produto estudado.

\section{APRESENTAÇÃO DO CENÁRIO INICIAL DO ESTUDO}

A empresa Guebb Jeans tem sua unidade de fabricação localizada no norte do estado do Rio Grande do Sul na cidade de Chapada. É uma empresa familiar de pequeno porte gerida pelos próprios proprietários, os quais cuidam desde as questões administrativas, desenvolver coleções e modelagem dos produtos, além de coordenar a produção e as atividades de vendas.

Trabalhando exclusivamente com tecido do tipo jeans, fabrica, bermuda, jaqueta e calça tanto masculina quanto feminina, sendo o seu produto principal a confecção de calça jeans masculina tradicional. Sua estratégia mercadológica está em duas ações principais, sendo a primeira para a venda de produtos da marca própria e outra na facção de outras marcas. Os produtos de sua marca são comercializados para todo o estado do Rio Grande do Sul, e os faccionando são principalmente para marcas de um grande grupo empresarial do ramo da confecção com diversas lojas no estado do Rio Grande do Sul.

Em uma área de aproximadamente $800 \mathrm{~m}^{2}$ a empresa Guebb Jeans possui suas instalações compondo dos setores nos quais os produtos percorrem agregando valor, sendo eles: corte; confecção (costura; lavanderia; acabamento e inspeção final) e a expedição.

Conta com 36 colaboradores, que entre eles estão os dois proprietários. No que se refere a equipamentos conta com 35 máquinas instaladas nos setor de costura que compreende corte, costura, e acabamento; no setor da lavanderia conta com 2 máquinas de lavar, 1 centrífuga e 3 secadoras; e, ainda para dar suporte à algumas máquinas no setor de costura, lavanderia e acabamento conta com 1 caldeira e 1 compressor de ar.

O estudo foi iniciado quando a empresa realizava a ampliação de seu ambiente e o estudo de instalações de novos equipamentos. Com essa ampliação da fábrica terá o dobro do espaço físico, com alterações significativas de localização de máquinas com o passar de toda a lavanderia para o térreo, além de contar com mais uma máquina de lavar que proporciona o dobro do desempenho da lavagem, uma nova caldeira com mais pressão e calor que possibilita o aumento da eficiência da máquina de passar, secadoras a quente e máquinas de lavar com água quente. 
Contará também estava projetado uma estação de tratamento de água, dando conta do tratamento e descarte adequado das águas despejadas pela lavanderia, estando de acordo com a legislação do meio ambiente em vigor.

Os setores estão distribuídos nas dependências internas da fábrica conforme sua estrutura física pré-existente, ilustrado na Figura 1, a área macro utilizada por cada um deles. Cada setor foi analisado de forma independente devido as diferentes formas de processamentos distintas entre eles, ou seja, cada caso é um caso a se abordar e analisar de forma isolada. Veja a seguir o estoque de matéria prima, o fluxo entre os setores, assim como, os estoques em aguardo de processamento e o estoque de produto acabado.

Inicialmente a empresa tinha uma baixa demanda de produção, seu leiaute era organizado de forma a facilitar os processos de produção aproveitando melhor o espaço disponível. Ao passar dos anos a produção aumentou significativamente principalmente pela ampliação de parcerias com grandes empresas do setor varejista, exigindo a aquisição de máquinas de maior tecnologia e contratação de mais funcionários e a estrutura física ficou pequena para acomodar de forma adequada as máquinas além de dificultar a movimentação de pessoal e de materiais nas dependências internas da empresa. Desta forma, impossibilitando um leiaute adequado e flexível para a produção que exige atualizações e modificações constantes em seus processos.

A estrutura inicial de análise exigia movimentação significativa de pessoal e de produto, gerando fluxos truncados em sua produção, estoque entre setores aguardando processamento, acarretando perda de eficiência e produtividade, podendo ser observado no leiaute atual da fábrica conforme os fluxos de materiais entre as máquinas e os departamentos.

Devido à falta de espaço físico principalmente no setor de costura, e pelo desbalanço de produção entre o setor de confecção e a lavanderia, gerando estoque elevado aguardando processamento para a lavanderia. Assim, se observa que o leiaute atual não está adequado a atividade desenvolvida devido à falta de espaço físico, impossibilitando a realocação de maquinário e um fluxo adequado da produção, bem como existe a necessidade de maior eficiência no setor da lavanderia, a fim de diminuir o tempo de processamento por produto ou aumentar a sua capacidade instalada, balizando o tempo de agregação de valor com outros setores da empresa.

A falta de espaço físico também prejudica o armazenamento de matéria prima. $O$ estoque é limitado e amontoado, dificultando a identificação, separação e movimentação de material, além de ocorrer em algumas vezes falta de material para a ordem de pedido, tendo que adiantar outra produção futura para não parar a empresa. $O$ estoque do produto acabado também é alocado em espaços disponíveis entre o setor de expedição e confecção, e conforme visto na Figura 1 do leiaute atual.

Seguindo o fluxo de produção em cada setor da fábrica, foi identificado e mensurado além de cada fase de agregação de valor, o tempo (em segundos) em cada fase. Desta forma foi possível identificar (em segundos) o tempo que o produto realmente sofreu transformação e agregou valor, a fim de comparar com o tempo total de cada lead time dos departamentos, identificando o tempo parado em que o produto deixou de agregar valor. 
Figura 1 - Leiaute da fábrica e fluxo de materiais no início do estudo

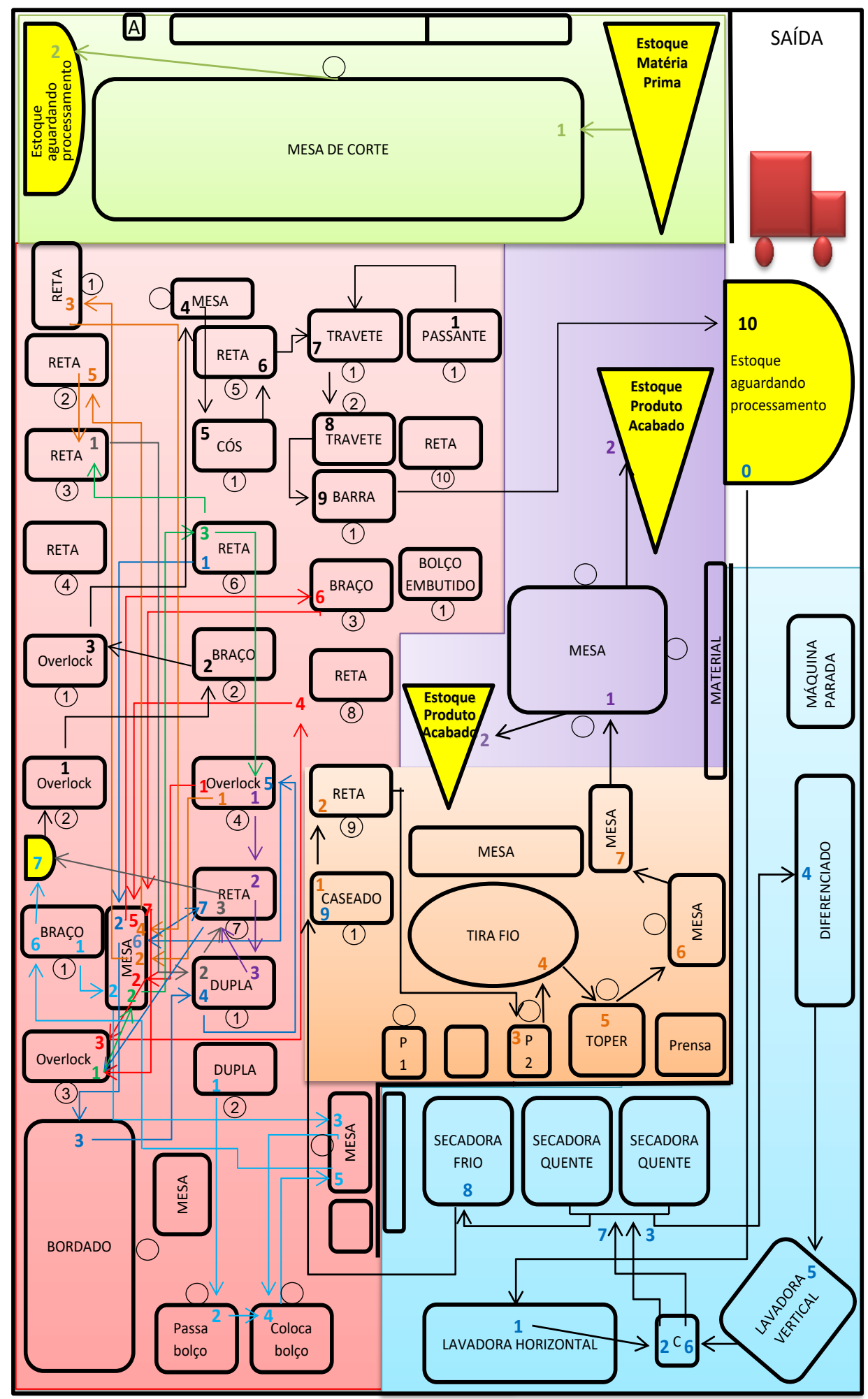

Departamento de corte

Departamento de confecção

Departamento de lavanderia
Departamento de acabamento

Departamento de expedição

Fonte: elaborada pelos autores 
O tempo de agregação de valor por setor, demonstrado na Figura 2, demonstra que o setor de confecção é o que mais agrega valor no desenvolvimento do produto, já que este setor é o que gera a maior transformação ao produto, representado por $1.259 \mathrm{~s}$, aproximadamente $21 \mathrm{~min}$. No entanto, em relação ao tempo de agregação de valor por funcionário por peça em cada setor observou-se que o tempo de agregação de valor por unidade produzida põe número de colaboradores, e no caso da lavanderia por máquinas, devido seus ciclos fechados, em cada departamento, constatou-se que a confecção é a que menos agrega valor por colaborador.

Figura 2 - Resultados agrupados dos tempos de cada processo

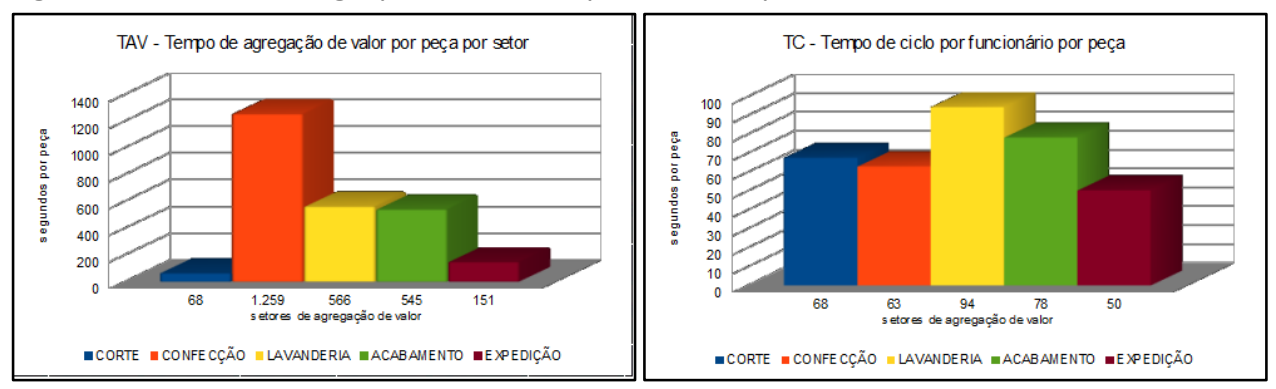

Fonte: elaborada pelos autores

Este desbalanceamento entre os setores foi observado pela amplitude dos tempos de cada processo, havendo tempos de 50s a 94s de agregação de valor por peça em diferentes departamentos. Isto demonstra que as diferenças são muito grandes, e que há necessidade de serem trabalhadas, buscando o balanceamento entre os setores.

Outro desbalanceamento observado foi observado pelo estoque aguardando processamento para a lavanderia. Este fato foi justificado devido a capacidade da lavanderia ser $49 \%$ menor em relação ao processo anterior, gerando acúmulo de produto aguardando processamento. Por não conseguir atender a demanda da confecção, este setor necessitava de aumento de eficiência mínima de 33\% a fim de equilibrar os tempos de agregação de valor por produto.

O setor de acabamento poderia trabalhar com $83 \%$ de sua capacidade que ainda vence o serviço da lavanderia. Mas este deve ter atenção, pois melhorando a eficiência da lavanderia, ele é o setor seguinte a ser trabalhado, pois ainda tem que melhorar em relação ao processo de confecção, sua eficiência deverá ser melhorada em $19 \%$ a fim de balizar seu desempenho com o setor de confecção.

A expedição tem capacidade suficiente para suprir todos os departamentos anteriores, pois seu tempo em agregação de valor é menor em relação aos demais.

A melhora na eficiência de cada setor pode ser pelo aumento do número de máquinas, ou com máquinas de maior capacidade, ou mais rápidas, ou com modificação nos seus fluxos e/ou processos, número de funcionários, enfim, cada setor tem um diferencial a ser estudado e analisado a fim de tomar a melhor decisão.

Em síntese, foram realizadas tomadas de tempo de fluxo de cada um dos processos da empresa e organizados gráficos de cada setor e com base na 
observação dos fluxos, processos e seus respectivos tempos identificaram-se problemas como, fluxos truncados, grande estoque de material aguardando processamento, necessidade de um espaço físico maior, tempos de agregação de valor irregulares entre os setores, assim como aumento do número de máquinas ou maior eficiência das mesmas.

Tendo por base o tempo de agregação de valor, que trata do tempo em cada elemento de trabalho que efetivamente transforma o produto de modo que o cliente esteja disposto a pagar por ele, foi desenvolvido um mapa de fluxo de valor que aponta os fluxos de informações e de materiais entre cliente, fornecedor e com seus processos, conforme Figura 3.

Figura 3 - Mapa do fluxo de valor inicial ao estudo

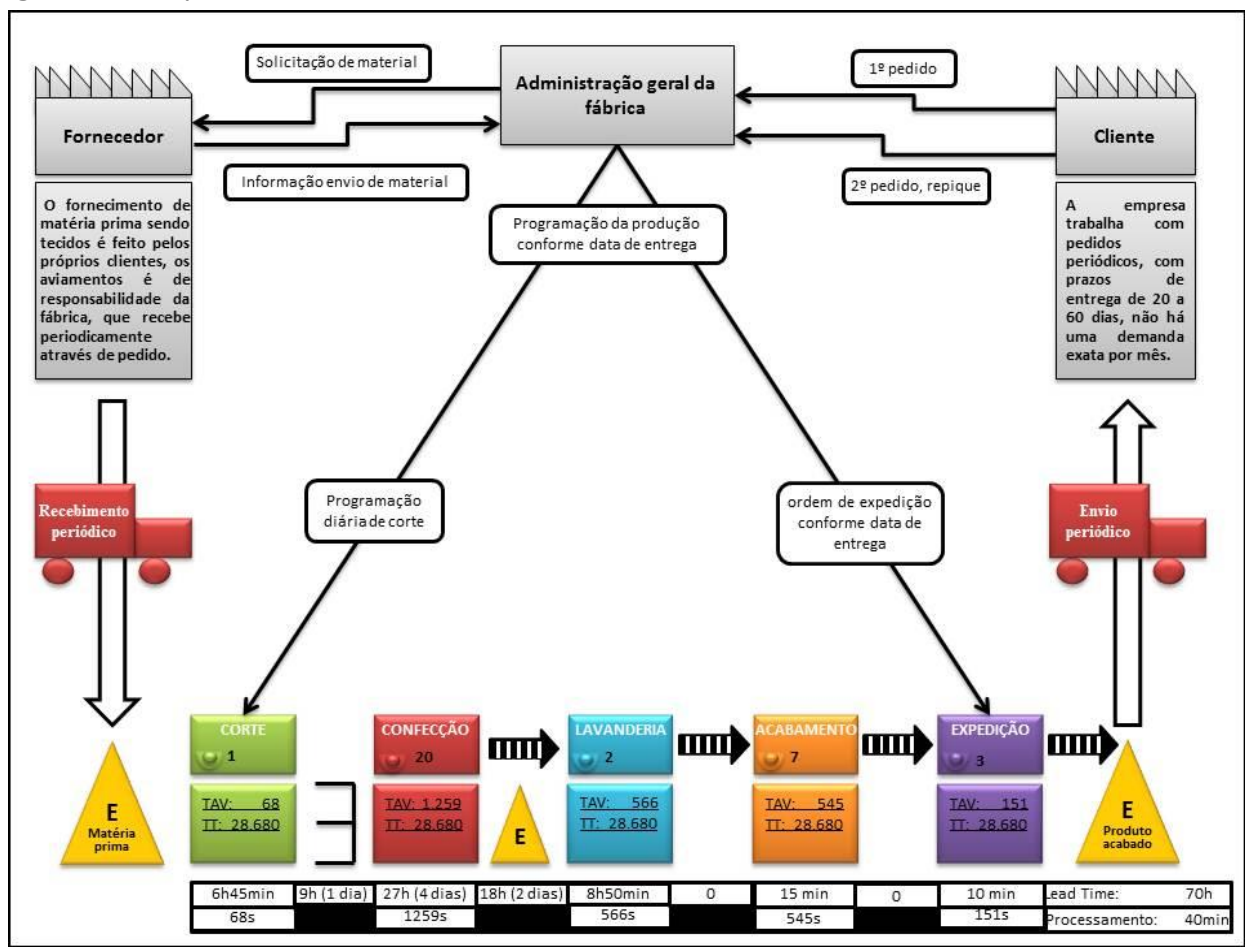

Fonte: elaborada pelos autores

Observa-se na referida figura o tempo de agregação de valor em cada processo e o lead time de produção, sendo o tempo que leva uma peça para percorrer todo o caminho no chão de fábrica, começando na entrada no primeiro departamento na qual se inicia pelo corte, passando pelos demais setores sofrendo transformações até se tornar um produto acabado. Salienta-se que esta organização gráfica não representa a real distribuição física das máquinas e o fluxo dos processos de fabricação.

Ao observar o mapa de fluxo de valor da empresa, pode ser visto um fluxo de informações da direita para a esquerda na parte superior e para os setores da empresa, seus fluxos de materiais da esquerda para a direita na parte inferior do mapa. Deste modo o mapa do fluxo de valor torna a confusão compreensível e trazem os tempos de agregação de valor 40 min e o lead time $70 \mathrm{~h}$ de uma forma comparativa com grande disparidade entre ambas. 
Com o intuito de minimizar a diferença entre os tempos de agregação de valor e o lead time total, dando maior eficiência à empresa de um modo geral, com maior fluidez em seus fluxos sugere-se um novo leiaute.

\section{PROPOSTA DE LAYOUT BASEADO NO MAPEAMENTO DO FLUXO DE VALOR}

A empresa está em ampliação dobrando pelo menos seu espaço físico, dando condições de remanejo e inserção de máquinas, havendo também a necessidade de inserir uma sala de designer e reunião no chão de fábrica, levando em conta algumas limitações de estrutura física e hidráulica das antigas e novas instalações, já abordadas no decorrer do trabalho. Desta forma foi elaborado um novo leiaute para a empresa conforme Figura 4.

Este modelo de sugestão de leiaute foi baseado no espaço ampliado, a partir da linha traçada no meio da figura, respeitando o espaço físico e suas instalações hidráulicas. Foi definida a sala de designer e reuniões conforme requisito da administração, a fim de atuar mais intensivamente no chão de fábrica.

Os fluxos de movimentação de material e o posicionamento das máquinas e equipamentos que auxiliam a produção sofreram alterações. Para melhor visualização os setores foram separados, ilustrativamente, por cores já utilizadas na Figura 1 para a elaboração do leiaute do estado atual. O setor de corte foi representado pela cor verde, confecção pela vermelha, a lavanderia foi para o subsolo não constante neste leiaute, acabamento na cor laranja e expedição com a cor roxa. Os espaços em branco representam o espaço disponível que a empresa tem para ampliação do quadro de máquinas ou remanejo do leiaute. 
Figura 4 - Novo leiaute sugerido

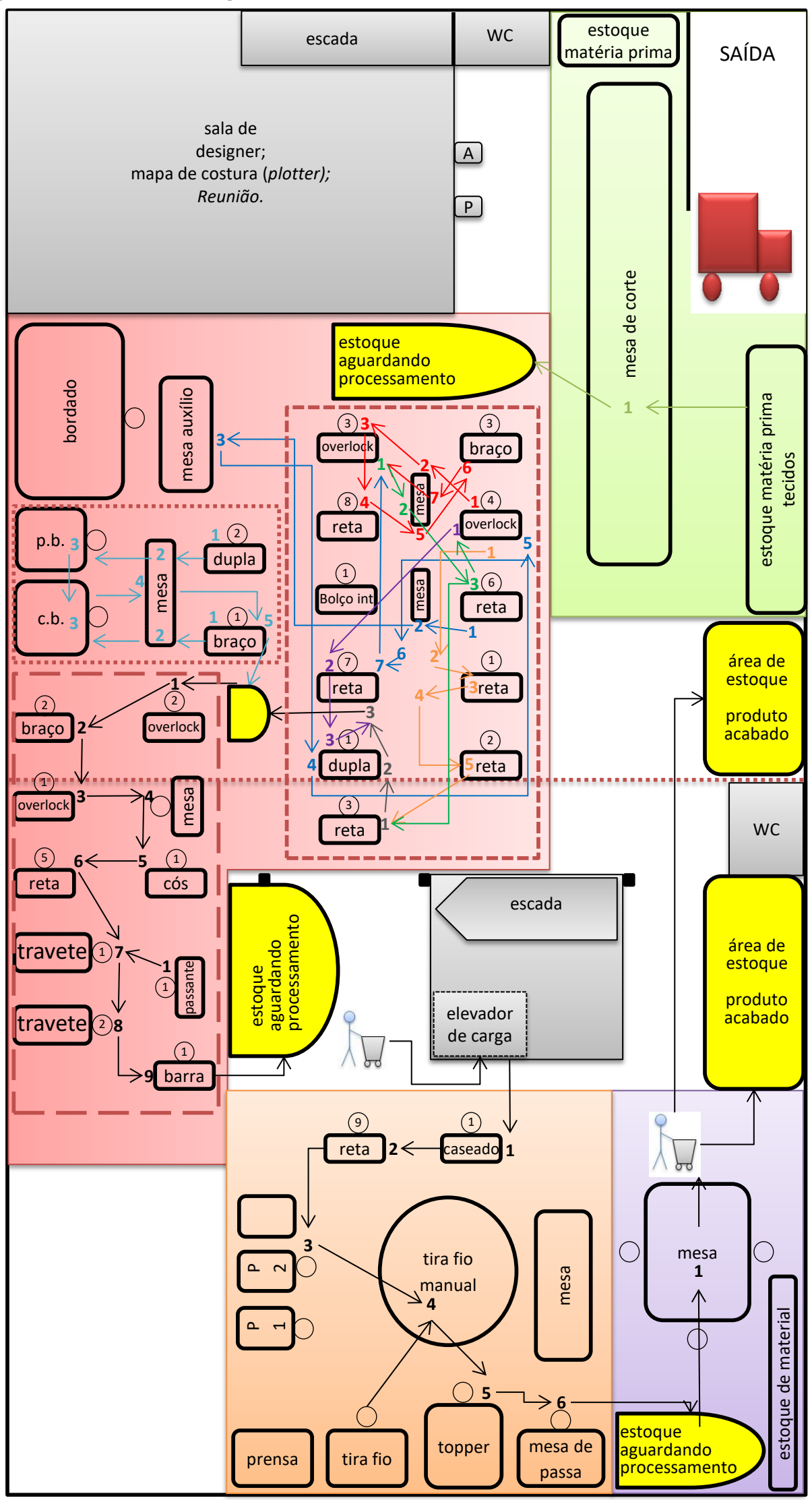

Fonte: elaborada pelo autor (2014) 
Buscou-se utilizar a mesma quantidade de máquinas da estrutura atual e foram inseridas outras que estavam guardadas e não operantes devido à falta de espaço, outras inseridas devido à aquisição visando o melhoramento da produção, estas já programadas pela administração.

Figura 5 - Novo leiaute sugerido para lavanderia

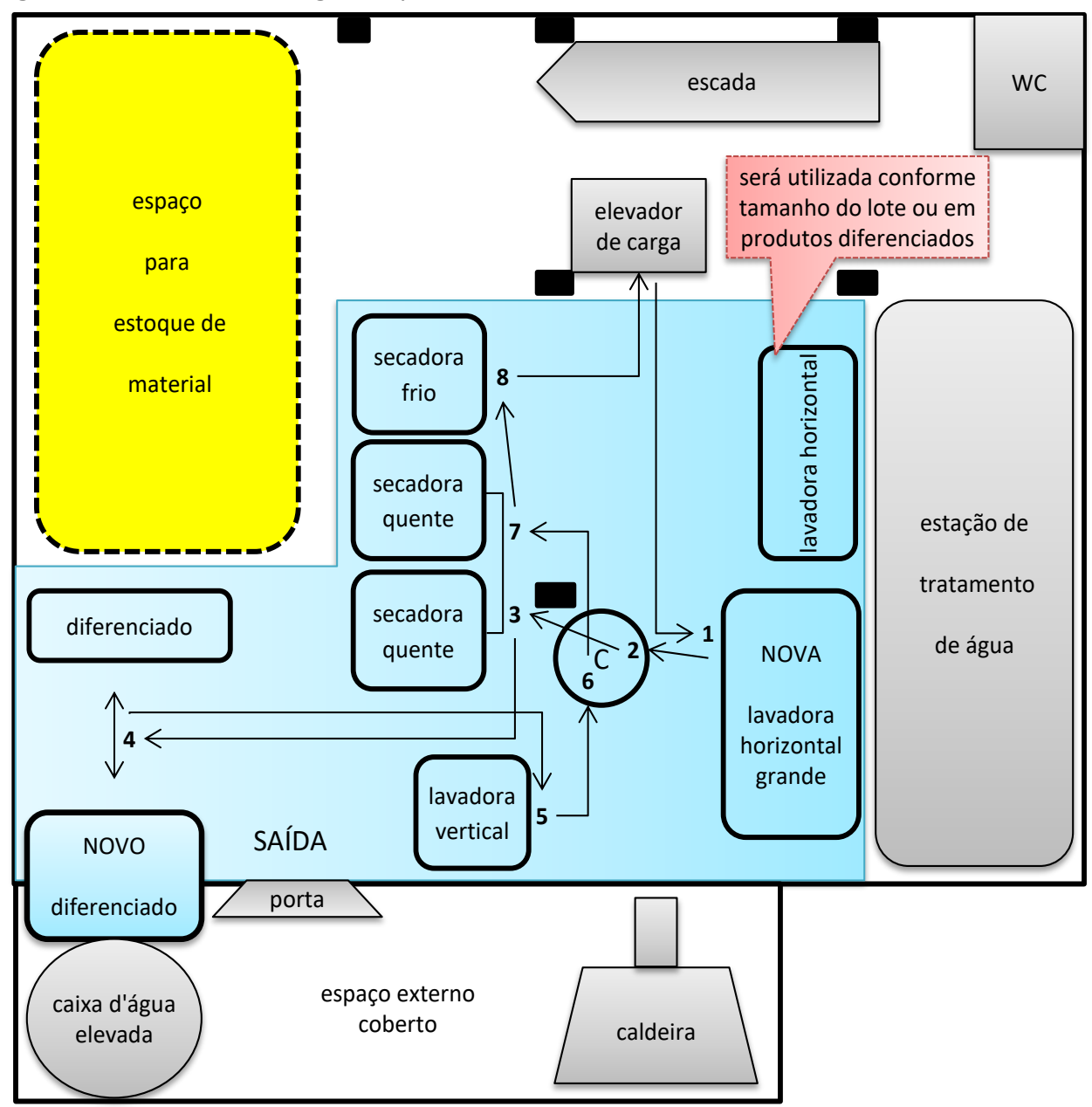

Fonte: elaborada pelos autores

Com a ampliação em extensão da fábrica, e devido à área geográfica apresentar possibilidade de uma ampliação na parte inferior da planta. A lavanderia ficou separada dos demais setores, tendo acesso por escadas e um elevador de carga, com um espaço ampliado, possibilitando a acomodação das máquinas atuais, mais alguns novos equipamentos, espaço para estoque de materiais e ainda dividindo espaço com os equipamentos de tratamento de água, conforme Figura 5.

Ao analisar os dados de tempos de produção e das quantidades produzidas, pode-se verificar que a principal necessidade apontadas foi a secadora horizontal. A empresa já adquiriu uma nova máquina, que trabalha com o dobro da capacidade produtiva da antiga máquina, ficando a antiga máquina para trabalhar em caso de necessidades de baixos lotes de produção e/ou destinada para produtos diferenciados. 
Outro equipamento que apresentou elevado tempo são as secadoras a quente, mas devido à aquisição de uma nova caldeira, elas trabalharão com temperatura mais elevada, e terão uma maior eficiência. Trabalharão com maior calor, sempre tendo o cuidado de não esquentar demais a peça para não danifica-la. Caso ainda não vencerem a produção será necessário à aquisição de mais uma secadora a quente.

O diferenciado recebeu uma nova cabine de tratamento, que além de agilizar o processo, oferecerá mais opções de tratamento na peça, assim como maior padronização nos detalhes de diferentes peças, gerando maior qualidade e padrão para o produto.

\section{CONSIDERAÇÕES FINAIS}

Este estudo teve como objetivo geral elaborar e analisar o mapa do fluxo de valor no processo de fabricação do produto calça jeans masculina na fábrica Guebb Jeans uma indústria de confecções e baseada na observação dos fluxos, processos e seus respectivos tempos propor um novo arranjo físico para a empresa. No decorrer do trabalho identificaram-se problemas como fluxos truncados, grande estoque de material aguardando processamento, necessidade de um espaço físico maior, tempos de agregação de valor irregulares entre os setores assim como aumento do número de máquinas ou maior eficiência das mesmas.

Diante do que foi apresentado neste estudo, pode-se observar que em relação ao problema de pesquisa que questionava quais contribuições que a ferramenta de análise de fluxo de valor propicia para a projeção de um novo arranjo físico a fim de atender as necessidades da empresa em estudo, percebese que são várias, como a identificação dos fluxos de materiais e de informações envolvidos na elaboração do produto estudado, também a identificação de gargalos de produção através da cronometragem pelo seu tempo de agregação de valor em cada unidade em que o produto percorre até tomar sua forma final, bem como a visualização pelo mapa do fluxo de valor e do estado atual a fim de corroborar para a projeção de um novo arranjo físico atendendo as necessidades da empresa.

Tendo por base o tempo de agregação de valor, onde trata do tempo em cada elemento de trabalho que efetivamente transforma o produto de modo que o cliente esteja disposto a pagar por ele e com o intuito de minimizar a diferença entre os tempos de agregação de valor e o lead time total, dando maior eficiência à empresa de um modo geral, com maior fluidez em seus fluxos, assim, foi projetado um novo fluxo de valor para a empresa.

Para a criação de um novo fluxo de valor, foi desenhado um novo leiaute que leva em conta algumas limitações de estrutura física e hidráulica das antigas e novas instalações, assim como as abordadas no decorrer do trabalho, chegando a uma sugestão de um novo leiaute em duas plantas de chão de fábrica, uma no nível da atual fábrica que sofreu um aumento e outra no nível inferior, pois com este aumento da mesma permitiu construir no nível inferior, este tipo de estrutura foi possível devido a instalação da fábrica estar em solo irregular. Este aumento da estrutura física já estava em projeto e encontra-se em andamento. 
Por fim salienta-se a importância dos dados obtidos para o planejamento e a tomada de decisão de um novo fluxo de valor. Obtendo os dados coletados documentados para fim de análise e comparações futuras com supostas melhorias implantadas. Outra sugestão é a aplicação deste estudo em todos os produtos faccionados pela empresa, a fim de descobrir seus tempos e buscar balizar a produção, pois nem todos os produtos desenvolvidos passam pela mesma linha projetada neste estudo, deste modo buscando balancear a produção da fábrica independente do produto fabricado, buscando atingir o melhor resultado independentemente do tipo de produção.

Assim justifica-se a realização deste estudo, bem como o cumprimento da maior parte dos objetivos e a resposta ao problema de pesquisa, desta forma acredita-se ter contribuído para com os ideais e necessidades da empresa, para a área acadêmica contribuiu para a formação como caso para estudo para futuros gestores como um momento oportuno de unir a teoria compreendida em sala de aula e a vivencia prática em um campo com situações e necessidades reais. Este estudo dirige-se a quem tiver interesse em conhecer mais sobre o tema mapeamento do fluxo de valor, um estudo prático realizado em uma indústria de confecções. 


\title{
Restructuring layout based on value stream mapping: A study in a clothing industry
}

\begin{abstract}
The aim of this study was to develop and analyze the map the value stream in the manufacturing process of the male jeans product, in a garment industry. The methodology used in approach was qualitative and quantitative, using the mode of action research procedure, applying techniques of direct observation and data collection on the shop floor, following the production operations, the trial took place only a model a collection of traditional male jeans, as this is the flagship of the company. The value stream mapping tool was used to identify the flow of processes, materials and current information on the company, in which bottlenecks have been identified, such as truncated flows, large inventory of stuff waiting to be processed, need for more physical space, irregular valueadding time between sectors as well as need to increase the number of machines or more efficient of them. With the data obtained in this study it was possible to design a new physical arrangement for all company departments, improving the workflow efficiency, helping to reduce cycle time and lead time of production.
\end{abstract}

KEYWORDS: Value Stream Mapping. Layout. Production. Making. 


\section{REFERÊNCIAS}

BUENO, W. P.; VEIGA, C. H. A. Estudo do mapeamento do fluxo de valor na formação do cabedal de calçados femininos. Revista Gestão Industrial, v. 12, n. 14, p. 127-149, 2016. DOI: 10.3895/gi.v12n4.4852 crossref

COLLIS, J.; HUSSEY, R.; Pesquisa em administração: um guia prático para alunos de graduação e pós-graduação. 2. ed. Porto Alegre: Bookman, 2005.

COOPER, D. R.; SCHINDLER, P. S. Métodos de pesquisa em administração. 10. ed. Porto Alegre: Bookman, 2011. 784p.

CORRÊA, H. L.; CORRÊA, C. A. Administração de produtos e operações:

manufatura e serviços: uma abordagem estratégica. 2. ed. São Paulo: Atlas, 2006.

DAVIS, M. M.; AQUILANO, N. J.; CHASE, R. B. Fundamentos da administração da produção. 3. ed. Porto Alegre: Bookman, 2001.

DUTRA, D. R.; FERREIRA, M. A. M.; GOMES, D. T.; SANTOS, L. M. Análise do desempenho de empresas do setor de confecções brasileiro sob a ótica da Teoria da Contingência Estrutural: um estudo empírico. Revista Gestão \& Tecnologia, v. 11, n. 2, pp. 1-18, 2011.

ELIAS, S. J. B.; OLIVEIRA, M. M.; TUBINO, D. F. Mapeamento do Fluxo de Valor: Um Estudo de Caso em uma Indústria de Gesso. Revista ADMpg Gestão Estratégica, v. 4, n. 1, 2011.

GADELHA, F. C.; BESSA, J. A.; BARROSO, D. A.; MENEZES, J. W. M.; ALEXANDRIA, A. R. Alteração de um layout funcional para layout celular motivados pelos fundamentos da manufatura enxuta: estudo de caso em indústria de transformadores. Holos, ano 31, v. 6, p.156-159, 2015.

GAITHER, N.; FRAZIER, G. Administração da produção e operações. 8. ed. São Paulo: Thomson Learning, 2007.

LIMA, M. M. X.; BISIO, L. R. A.; ALVES, T. C. L. Mapeamento do fluxo de valor do projeto executivo de arquitetura de um órgão público. Gestão \& Tecnologia de Projetos, v. 5, n. 1, 2010. DOI: 10.4237/gtp.v1i1.113 crossref

MARCONI, M. de. A.; LAKATOS, E. M. Fundamentos de metodologia científica. 6. ed. São Paulo: Atlas, 2009. 
MARTINS, Petrônio Garcia; ALT, Paulo Renato Campos. Administração de Materiais e Recursos Patrimoniais. 2. ed. São Paulo: Saraiva, 2006.

MOREIRA, D. A. Administração da produção e operações. 2. ed. São Paulo: Cengage Learning, 2008.

NOGUEIRA, R. R.; COTRIM, S. L.; LEAL, G. C. L. Implantação do lean seis sigma em uma indústria de fios têxteis. GEPROS. Gestão da Produção, Operações e Sistemas, Bauru, Ano 12, no 2, abr-jun/2017, p. 67-92. DOI:

10.15675/gepros.v12i2.1634. crossref

OLIVEIRA, R. C. M.; CORRÊA, V. A.; NUNES, L. E. N. P. Mapeamento do fluxo de valor em um modelo de simulação computacional. Revista Produção Online, v.14, n. 3, p. 837-861, jul./set. 2014. DOI: http://dx.doi.org/10.14488/16761901.v14i3.1461 crossref

ROTHER, M.; SHOOK, J. Aprendendo a enxergar: mapeando o fluxo de valor para agregar valor e eliminar o desperdício. São Paulo: Lean Institute Brasil, 2003.

SALGADO, E. G. et al. Análise da aplicação do mapeamento do fluxo de valor na identificação de desperdícios do processo de desenvolvimento de produtos.

Gestão \& Produção, v. 16, n. 3, p. 344-356, jul.-set. 2009. crossref

SANT'ANNA, M. R. Moda e produto: série moda palavra. v. 6, Florianópolis/São Paulo: Estação das letras e cores, 2010. 256p.

SANTOS, L. C.; GOHR, C. F.; SANTOS, E. J. Aplicação do mapeamento de fluxo de valor para a implantação da produção enxuta na fabricação de fios de cobre. Revista Gestão Industrial, v. 07, n.04: p. 118-139, 2011. D.O.I.: 10.3895/S180804482011000400006

SEBRAE. Comece certo: indústria de confecção. 3. ed. São Paulo, 2010.

SEIXAS, C. A. de; CATORIA, M. L. B. Panorama da moda no Brasil e suas interfaces com a moda internacional. REDIGE, 4 v., 3 n., dez. 2013.

SHINGO, S. O Sistema Toyota de Produção. 2a ed. Porto Alegre: Bookman, 1996.

SILVA, M. S. Q.; ALVES, J. M. Aplicação do método de mapeamento de fluxo de valor na cadeia de suprimentos de eletrodomésticos. Simpósio de Administração da Produção, Logística e Operações Internacionais, 14, 2011. Anais... SIMPOI, 2011. 
SLACK, Nigel; CHAMBERS, Stuart; JOHNSTON, Robert. Administração da Produção. 2. ed. - 8. reimp. São Paulo: Atlas, 2008.

STRAUSS, A.; CORBIN, J. Pesquisa qualitativa: técnicas e procedimentos para o desenvolvimento de teoria fundamentada. 2. ed. Porto Alegre: Artmed, 2008. $288 p$.

THIOLLENT, M. Metodologia da pesquisa-ação. 12. ed. São Paulo: Cortez, 2003.

TRIPP, D. Pesquisa-ação: uma introdução metodológica. Educação e pesquisa, v. 31, n. 3, São Paulo: set./dez. 2005, 443-466 p.

TUBINO.D.F. Planejamento e controle da produção. Teoria e prática. São Paulo: Atlas, 2007.

UNIVERSIDADE DA AMAZÔNIA. Curso de tecnologia em gestão de empresas: gestão de produção, layout ou arranjo físico. Disponível em: <http://arquivos.unama.br/nead/proead/Tec_gestao_empresas/gestao_produca o/html/unidade4/unidade_4page_3.html>. Acesso em: 25 jul. 2014.

VEIGA, C.H.A.; CERESA, D. Mapeamento do fluxo de valor do desenvolvimento de mostruários: uma investigação em uma indústria de confecções. Redige, v. 4, n.2, 2013.

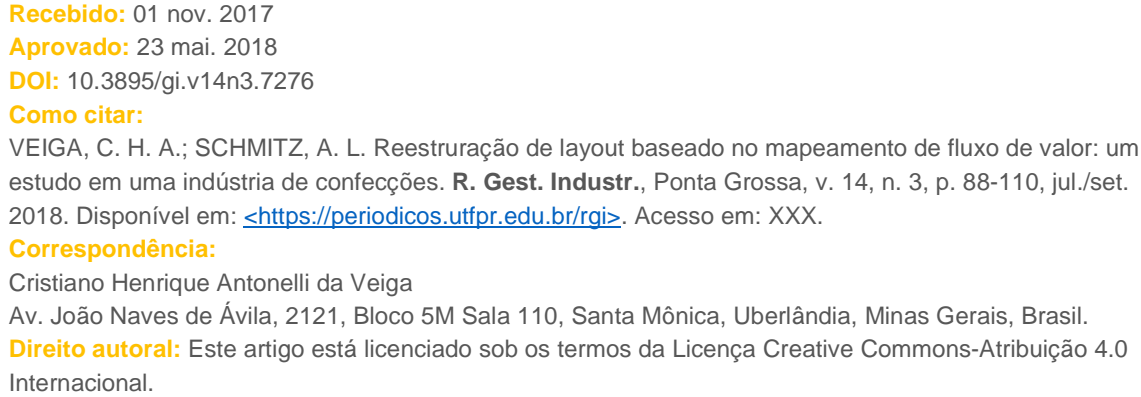

